\title{
Evolution of risk assessment methods and the possibility of their use in determining the investment and construction projects'
} effectiveness

\author{
Ekaterina Kazaku ${ }^{1}$, Elena Zvereva $^{1 *}$, and Julia Tsarionova $^{2}$ \\ ${ }^{1}$ Emperor Alexander I St. Petersburg State University of Railway Transport, 190031, St. Petersburg, \\ Russia \\ ${ }^{2}$ Far Eastern State Transport University, 680000, Khabarovsk, Russia
}

\begin{abstract}
The study is devoted to identifying the main trends in the development of the theory of evaluating the effectiveness of investment and construction linear-extended projects, the implementation of which is carried out with the participation of public investments of different levels, as well as those of socio-economic importance for the construction region and Russia as a whole. Global informatization, penetrating into all spheres of human activity, determines the digital economy formation as an economic activity operating in the digital space. This means that digital material data is a key factor in production, processing of which in large volumes, compared to traditional forms of management, makes it possible to increase the economic activities efficiency. Methods of qualitative and quantitative risk assessment and accounting for the uncertainty of investment projects have been applied. In most theoretical directions, the preference is given to the use of the cost effectiveness criterion; methods of qualitative assessment and risk identification; introduction of modern digital methods of risk assessment and uncertainty accounting (Monte Carlo method, method of integral convolutions of numbers). There is no universal theoretical approach that reveals the investment process essence through the return on investment, which makes it possible to reliably assess the economic efficiency in construction ICP in the digital economy. It was revealed that the implementation of investment and construction projects (ICP) suggests the need to supplement the theoretical foundations, taking into account their specificity in terms of the effects taken into account, as well as uncertainty factors. The development of efficiency theory and, as a consequence, an increase in the basic data collection speed in the digital economy, as well as an increase in the reliability of efficiency estimates due to mathematical methods for quantifying risk and uncertainty. The implementation of investment and construction projects plays an important role in the transport industry.
\end{abstract}

*Corresponding author: zverelv@mail.ru 


\section{Introduction}

Global informatization, penetrating into ever large spheres of human activity, determines the formation of the digital economy as an economic activity operating in the digital space. This means that digital data is becoming a key factor in production. Their processing in large volumes in comparison with traditional forms of management makes it possible to increase the economic activity efficiency.

The formation of the digital economy defines a new stage in the development of the theory of investment efficiency assessment, the center of which is the technology of using digital data to substantiate, assess and monitor investment efficiency, based on the uncertainty factors' identification, assessing the level of risk and constructing probability distributions of investment efficiency indicators.

The implementation of investments in linear capital-intensive transport facilities is accompanied by the allocation of a separate business unit - an investment project - in order to justify the feasibility, volume and timing of investments, the development of a detailed business plan, as well as its implementation.

Within the framework of this study, investment and construction projects (ICP) are considered, the implementation of which is carried out with the participation of public investments of different levels, as well as those of social and economic importance for the construction region and Russia as a whole.

\section{Purpose of the study}

To achieve the main trends' identification in the development of the theory of assessing the investments' effectiveness in the field of transport construction in the digital economy, it is necessary to analyze the existing system of methods for assessing the effectiveness of investment and construction projects in the digital economy:

- to provide a historical overview of the investment efficiency theory formation;

- to build a classification of efficiency assessment methods ICP in the digital economy;

- to describe the main methods for assessing effectiveness ICP in the digital economy;

- to analyze the application features of the simulation methods to assess ICP effectiveness in the digital economy;

- to provide a business case for the use of probabilistic assessment methods.

\section{Research methodology}

Determination of the effectiveness of investments in ICP construction is carried out on the basis of both deterministic methods and probabilistic methods, taking into account uncertainty and risk. It should be noted that the beginning of the risk assessment should be associated with the work of F.Kh. Knight [17] in 1921, who examined quality and risk assessment within the framework of financial theory. The world economic crisis has determined the formation of practical interest in some issues of forecasting, analysis and risk assessment.

The development of risk theory was due to the scientific developments of G. Markowitz and J. Danzig [6], who in 1952 proposed a method for taking into account risk when choosing investment portfolios, based on the profitability estimates and standard deviation of each portfolio. The main block of risk theory was formed in Russia at the beginning of the XX century. Legislative acts were developed to highlight the existence of production and economic risks. Nevertheless, by the mid-30s of the XX century, risk was excluded from scientific terminology, was ranked among the phenomena of the capitalist economy 
on the basis that it could not be combined with the planned economy of the USSR. Since the beginning of perestroika and the formation of a market economy in Russia at the end of the 20th century, the interest in the issues of risk assessment and accounting in the investment area was renewed.

In the field of the activity devoted to railway construction, the issues of risk assessment and uncertainty are disclosed less than in the related fields of activity. In the current industry methodologies [1, 2], based on methodological recommendations [14], the concept of risk is disclosed as an uncertainty associated with the possibility of adverse situations and consequences occurring during the project implementation [15]. The concept of uncertainty is accepted as incompleteness and (or) inaccuracy of information about the conditions for the project implementation. Understanding risk as uncertainty determines the formation of a risk assessment methods' system based on subjective qualitative assessments.

The risk adjustment method, presented in 1998 was the first applied method which took into account risk and uncertainty. In 2008, an industry-specific method of socio-economic efficiency was developed [16], in which, when calculating the performance indicators, it was recommended to take into account that: "some well-known a fixed scenario, as there is no risk and uncertainty". Methods for analyzing the sensitivity of the project to changes in individual parameters and the analysis of the project implementation most hazardous scenarios for society are proposed.

Ensuring the results' reliability of assessing the effectiveness of investments in construction ICP based on the integration of existing methods for assessing the effectiveness of investments and investment features of railway construction.

The system of methods for assessing risk and accounting for uncertainty should be disclosed using the signs of classification: direct or indirect nature of the result obtained (direct, indirect); the nature of the resulting risk assessment (qualitative, quantitative); the nature of accounting for the time factor (static, dynamic); the nature of accounting for uncertainty (using a distribution function, discretely); method of finding the resulting indicator (simulation, analytical).

The analytical method for determining the results is focused on obtaining the values of exogenous variables. The simulation method is based on the step-by-step finding of the resulting indicators. Dynamic models, unlike static ones, take into account the time factor.

Methods of indirect assessment involve the use of technologies for adjusting and varying parameters, which leads to the assessments subjectivity and forms a lower degree of the results' reliability.

Indirect assessment methods are formed on the basis of two groups of methods: stability assessment (aggregated stability assessment, method of reliable equivalents, parameter variation method, regression analysis) and sensitivity analysis (break-even analysis, breakeven point analysis, sensitivity analysis, factor analysis).

Stability is checked by adjusting the parameters and obtaining the values of the studied indicator. Application of the sustainability aggregated assessment method [1] is based on moderately pessimistic forecasts of project parameters, the allocation of a reserve of funds for unforeseen expenses, as well as a change in the discount rate $E_{r}$ by the amount of correction for risk. The expert determines the critical points of the project and assigns the amount of correction for risk. The method is widely used, but its subjectivity reduces the confidence degree in the results.

The basic concept of the reliable equivalents' method [12] is to adjust the simulated values of the cash flow elements. The correction is carried out through the use of decreasing coefficients determined by the analyst, which leads to insufficient reliability of the results.

The parameter variation method combines the sensitivity analysis method and the 
scenario method. The expert generates scenarios with different sets of key project parameters. A positive decision is made in case of a positive value of the resulting indicator in all cases.

Regression analysis $[5,25]$ is based on the use of dependencies of changes in the main uncertainty factors to determine predictive performance indicators. The dependences obtained on the statistical data basis are taken into account in the model by using the coefficients that determine the risk level. The laboriousness of substantiating the revealed dependences, taking into account the correlation, reduces the results' reliability.

Sensitivity analysis methods $[1,8]$ are advisable to apply when studying the influence of risk factors on the indicator under study. Some of the methods demonstrate the ratio of break-even sales to project sales (the method of analyzing break-even levels), the other part marks the critical points of the project parameters (the method of analyzing the break-even point). Sensitivity analysis methods are often used to determine the performance indicators' elasticity to individual parameters (factor analysis).

Direct methods include two groups: qualitative and quantitative assessment. The group of qualitative methods includes the method of expert assessments, the method of analogy, the method of analyzing the relevance of costs, etc. The key characteristic of these methods is their dependence on the experience and qualifications of experts, which affect the reliability of the results.

Quantification methods are:

- methods taking into account quantitative characteristics of uncertainty (decision trees, interval model method, fuzzy set method, scenario method);

- Value at risk method (VAR);

- simulation methods (Monte Carlo and integral convolutions of numbers).

The decision tree methods [12], the scenario method [4, 22], the interval models method [1], and the fuzzy set method [23, 25] are based on the method for assessing the expected effect taking into account the quantitative characteristics of uncertainty. These methods take into account the implementation of different scenarios, taking into account their probabilistic characteristics, established by an expert, with their help determine the risk of project inefficiency as the sum of the probabilities of all scenarios that do not meet the efficiency criterion.

VAR method [18] reflects the stability degree of the investment portfolio, when the losses level is calculated, which does not exceed the losses level in the entire portfolio value for a certain period. The losses level is taken into account in the model with a given probability.

Monte Carlo methods [7, 9, 10, 11, 26, 27] are based on the distribution laws of the selected uncertainty factors and the calculation of the average value of the desired efficiency indicator based on the simulation of the random factors' implementation using a pseudo-random number generator. They are widely used in the financial sector.

S.A. Koshechkin [7], A.P. Kuvshinov and A.V. Lukashov [9, 13] combined the Monte Carlo method with sensitivity analysis and scenario methods.

The innovative method of integral convolutions of numbers [19] was first applied by S.G. Oparin. It gives a possibility to construct a discrete risk function for a large number of uncertainty factors by reusing the operation of integral convolutions of numerical sequences. O. A. Tretyakov and S.G. Oparin [19, 24] applied the method of integral convolutions of numbers to assess the risk of not receiving the expected effects during trading. Yu.E. Gurov and S.G. Oparin [3, 20] implemented a method for assessing the socio-economic assessment of the effectiveness of road construction in terms of the "risk of non-receipt of the expected integral effect". S.G. Oparin together with A.E. StasishinaOlshevskaya [21], in the study of risk, give great importance to its identification, as well as 
risk assessment, taking into account the factors associated with the contractual system and the pricing system.

For a more visual representation of the existing trends in the development of the investments' effectiveness evaluating theory, an economic justification was carried out. The following methods are highlighted (table): risk correction method, Monte Carlo method, integral convolution method. The result of the risk adjustment method is a single value for the payback period, which reflects the average estimate. The accuracy of the risk adjustment method estimate is about $5 \%$ in comparison with the estimate of the mean by the method of integral convolutions of numbers. It is impossible to draw a conclusion about the reliability level of the assessment using the risk adjustment method.

The Monte Carlo method makes it possible to judge with a probability of $50 \%$ about the achievement of the investment payback period. The reliability of the estimate obtained changes in accordance with the standard deviation. The error in estimating the mean is 0.79 months. Thus, the boundaries of the change in the payback period are in the range from 120 to 130 months. The results accuracy of the average estimate by the Monte Carlo method in comparison with the method of integral convolutions of numbers reaches $0.8 \%$.

\section{Conclusion}

Thus, according to the study results, it should be concluded: there is no universal theoretical approach that reveals the essence of the investment process through the return on investment, which allows to reliably assess the economic efficiency of investments in the construction of investment and construction projects in the digital economy. Note that the implementation of an investment and construction project involves the need to supplement the theoretical foundations, taking into account their specificity in terms of the effects taken into account, as well as uncertainty factors.

In this study, an analysis of the existing system of methods for assessing the investment and construction projects' effectiveness in the digital economy is carried out, a historical review of the theory of investment efficiency is carried out, on the basis of which the gradual inclusion of the investment efficiency theory in the digital space is revealed.

The analyzed classification of methods for assessing the effectiveness of investment and construction projects made it possible to reflect the most used and widespread digital methods in assessing the effectiveness of investment and construction projects, as well as to identify the main characteristics of methods for assessing the effectiveness of investment and construction projects in the digital economy.

This paper analyzes the features of the simulation modeling methods' application to assess the effectiveness of investment and construction projects in the context of the economy digitalization. The comparison results of the methods for probabilistic efficiency assessment indicate that the method of integral convolutions of numerical sequences makes it possible to assess the risk most accurately and reliably not only for the average, but also at the ends of the distribution. With this approach, such a design solution turns out to be effective, which inspires confidence and has an acceptable risk of implementing an investment project under conditions of uncertainty and randomness of the considered risk factors.

As the main trends of the study, it should be noted:

- a significant role among the performance indicators in the considered scientific works is played by the value indicator of net present value, however, the indicator of the payback period reflects the essential side of long-term investments to a greater extent;

- due to the mathematical calculations laboriousness, more attention is paid to the methods of qualitative assessment, while quantitative assessment will provide a higher accuracy of the assessment results; 
- in the field of accounting for uncertainty and risk, the range of modern digital methods is gradually expanding (the Monte Carlo method, the method of integral convolution of numbers).

Economy digitalization leads to an increase in the basic data collection speed, as well as their reliability for assessing efficiency, which will increase the importance of mathematical methods for quantifying risk and uncertainty.

In further studies, attention will be paid to the following areas in the context of the economy digitalization: 1) identification of the assessment theory social aspect and monitoring of the investment and construction projects' effectiveness; 2) identification of risk as a socio-economic category of investment and construction projects; 3 ) analysis of time, economic, social, mathematical and information bases for assessing the investment and construction projects' effectiveness; 4) development of a system of criteria and indicators and methods for assessing and monitoring the investment and construction projects' effectiveness.

\section{References}

1. B.A. Volkov, V.Ya. Shulga, A.A. Gavrilenkov, Assessment of economic efficiency and innovation in railway transport: textbook. allowance ("Training and Methodological Center for Education in Railway Transport", M., 2009)

2. M.V. Gracheva, S.Ya. Babaskin, I.M. Volkov, ed. M.V. Gracheva, Risk analysis of an investment project: Textbook for universities (Unity - Dana, M., 2001)

3. Yu.E. Gurova, Bulletin of St. Petersburg State Transport University, SPb 3(24), 216 226 (2010)

4. A.A. Drokin, Financial risk management 1, 68 - 79 (2009)

5. Yu.A. Zakharov, Development of risk assessment models for investment projects of financial leasing, $\mathrm{PhD}$ Thesis, specialty: "Mathematical and instrumental methods of economics", 08.00.13 (Moscow Aviation Institute, M., 2007)

6. Information business portal: Methods for optimizing an investment portfolio according to the model of G. Markowitz, http://www.market-pages.ru/invest/12.html //( date of the application: 11.07.2020).

7. S.A. Koshechkin, Methods of quantitative analysis of the risk of investment projects, BusinessCom, http:/www.koshechkin.narod.ru (access date 25.04.2021).

8. A.V. Kruppa, Management of investment resources of an industrial enterprise in conditions of risk and uncertainty, $\mathrm{PhD}$ Thesis, specialty: "Economics and management of the national economy: organization and management of enterprises, industries, complexes", 08.00.05 (M., 2009)

9. A.P. Kuvshinov, A.V. Lukashov, Corporate Finance Management: St. Petersburg 3, 154 - 157 (2009)

10. A.P. Kulikovskiy, M.A. Lukyanova, Modeling the risk assessment of an investment project based on the Monte Carlo method, Proceedings of the Conference, Simferopol: (IEiU) 86 - 87 (2017)

11. A. A. Lobanov, A. V. Chugunov, Encyclopedia of financial risk management (Alpina Publisher, M., 2003)

12. I.Ya. Lukasevich, Financial risk management 4, 306 - 324 (2006)

13. A.V. Lukashov, Corporate finance management 1, 22-39 (2007) 
14. Methodological recommendations for assessing the effectiveness of investment projects (Second edition, revised and supplemented) (Approved. Ministry of Economy of the Russian Federation, Ministry of Finance of the Russian Federation and Gosstroy of the Russian Federation from 21.06.1999 No. 477) (Moscow,1999)

15. Methodological recommendations for the assessment of investment projects in railway transport (Appendix to the instruction of the Ministry of Railways of Russia dated August 31, 1998. N B-1024u) (Ministry of Railways of Russia, Moscow, 1998)

16. Methodology for assessing the socio-economic efficiency of the construction of new railway lines. JSC "Russian Railways" with the participation of specialists from ISA RAS, headed by, professor V. N. Livshits (JSC "VNIIZhT", SGUPS, 2008)

17. F.Kh. Knight, Risk, uncertainty and profit (Translation from English M. Ya. Kazhdan; edited by V.G. Grebennikov) (Series: Modern institutional and economic theory.) (Delo, M., 2003)

18. A.N. Nefedov Mathematical modeling, assessment and selection of multi-period investment projects in conditions of risk, $\mathrm{PhD}$ Thesis, specialty: "Mathematical modeling, numerical methods and program complexes", 05.13.18, (Tver State University, Tver, 2008)

19. S.G. Oparin, Yu.I. Teterin, Reliability and quality control 2, 57 - 68 (1991)

20. S.G. Oparin, E.V. Esipova, and Yu.E. Gurova, Probabilistic assessment of the efficiency of investments in transport construction taking into account uncertainty and risk by the method of integral convolutions of numerical sequences, Intern. scientific conference "Transport of the 21st century", Warsaw, 2010

21. S.G. Oparin, A.E. Stasishina-Olshevskaya, Method of identification and construction of the risk profile of investment projects when carrying out their cost assessment, Proceedings of the conference (RISKE -2018), SPB 72 - 83 (2018)

22. T.K. Retinskaya, Assessment of the risks of real investment projects: $\mathrm{PhD}$ Thesis, specialty: "Economics and management of the national economy: theory of management of economic systems; macroeconomics; economics, organization and management of enterprises, industries, complexes; innovation management; regional economy; logistics; labor economics ", 08.00 .05 (Nizhny Novgorod State Technical University, Nizhny Novgorod, 2009)

23. V.V. Romanov, Modeling a quantitative assessment of the risk of an investment project under conditions of uncertainty, $\mathrm{PhD}$ Thesis, specialty: "Mathematical and instrumental methods of economics", 08.00.13 (Perm State University, Perm, 2005)

24. O.A. Tretyakov, Method of economic analysis of risks during contract bidding in transport construction, $\mathrm{PhD}$ Thesis, specialty: "Economics and management of the national economy: theory of management of economic systems; macroeconomics; economics, organization and management of enterprises, industries, complexes; innovation management; regional economy; logistics; labor economics ", 08.00 .05 (SPb., 2005)

25. N.P. Udal, Methodology for assessing the risk of an investment project for various levels of uncertainty of design information, $\mathrm{PhD}$ Thesis, specialty: "Finance, money circulation and credit", 08.00.10, (Moscow Institute of Entrepreneurship and Law, M., 2007)

26. Q. Zhao, G. Liu, G. Gu, Journal of Mathematical Finance 3(4), 431-436 (2013). doi: 10.4236/jmf.2013.34045.

27. D. Ding, Q. Fu, J. So, Technology and Investment 3 (2), 121 - 125 (2012). doi: 10.4236/ti.2012.32015. 